\title{
Human Resource Management: The Importance of Getting It Right
}

\section{By Barry H. Dunn, Guest Editor}

I believe the real difference between success and failure in a corporation can be very often traced to the question of how well the organization brings out the great energies and talents of its people.

-Thomas J. Watson, Jr. former president of IBM

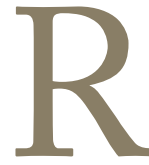

ecently a rancher related to me that his ranch foreman and two ranch hands all had been with him for over 25 years. His humble response to my congratulations on this feat was, "Lucky, I guess." I contend that luck had little to do with it. In his answer to my probing further about this remarkable accomplishment, it was clear that when he hired his crew, he had consciously and carefully selected individuals who offered the skills and competencies that best matched those required of the positions he had on his ranch, and that he had followed that up by successfully cultivating relationships built on clear communication and mutual trust and respect. He now has the reputation as an excellent employer, one for whom people want to work, but who also has zero

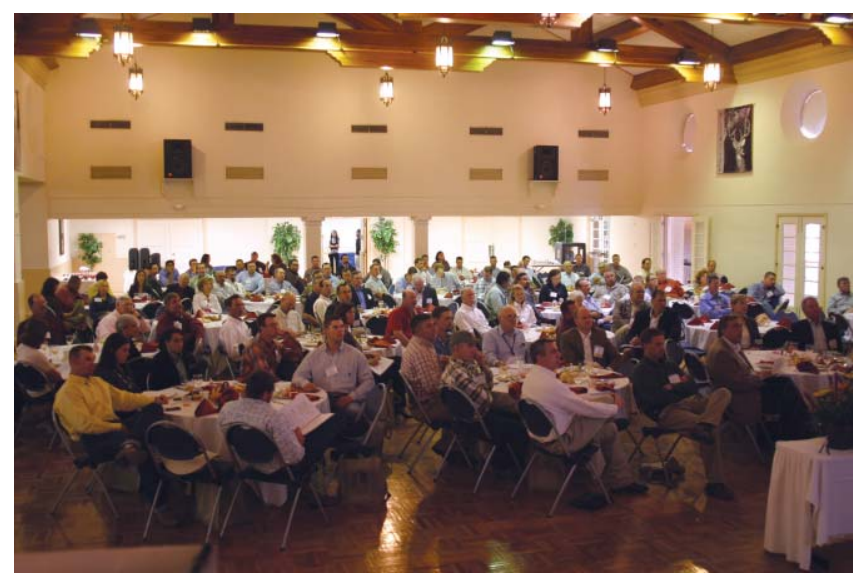

Participants at the Sixth Annual HOLT CAT ${ }^{\circledR}$ Symposium on Excellence in Ranch Management. Courtesy King Ranch Institute for Ranch Management. employee turnover. He also has an excellent ranch that is highly productive.

Finding, hiring, motivating, and keeping productive employees ranks as one of the most challenging responsibilities for owners and managers of any organization, including ranches. The work associated with this challenge is generally referred to as human resource management. The responsibility for managing human resources on a ranch falls directly in the lap of the ranch owner or manager. In spite of its proven track record, many businesses, including many ranches, have chosen not to work on the skills and tools necessary for successful human resource management. The reasons offered generally center around the relevance and importance of these skills in relatively small organizations. However, the fewer employees an organization has, the more dependent it is on the employees it does have, arguably making human resource management even more important.

Finding and keeping quality ranch employees is absolutely necessary if profitability, growth, and excellence goals are to be reached by any ranch. Former Chrysler CEO Lee

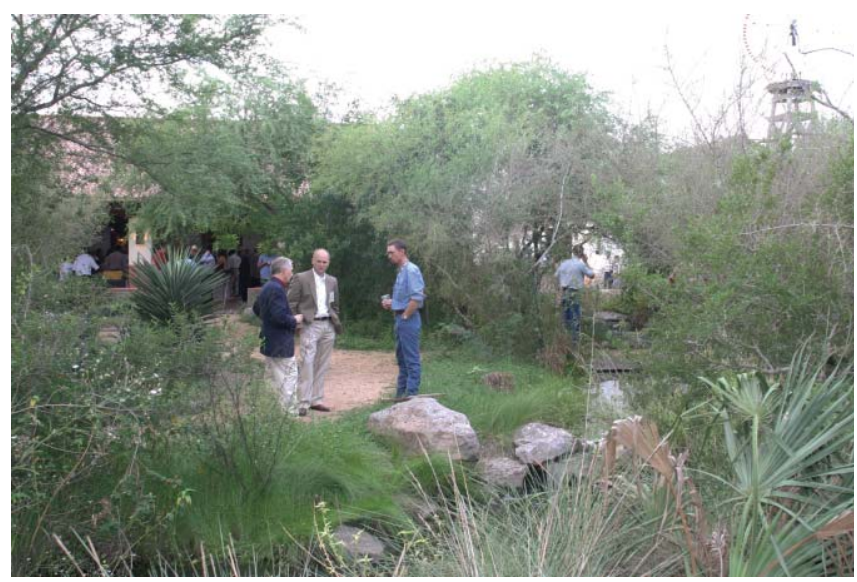

Symposium participants discuss what they are learning about human resource management during a break. Courtesy King Ranch Institute for Ranch Management. 
Iacocca points out that this process entails "starting with good people, laying out the rules, communicating with employees, motivating them and rewarding them." To that end, planning and management are essential to ensure that the right individuals are hired for specific jobs on the ranch and that processes are in place to keep them on the job.

The core of human resource management principles is the understanding that most people want to succeed and be part of a winning team. By developing a workplace focused on motivating and engaging ranch employees, workforce performance and job satisfaction often soar. As a result, overall productivity and efficiency improve, and the ranch begins to build a reputation as a great place to work. How can employee productivity and satisfaction be improved and ranch efficiency and success be achieved? Implementing proven, research-based human resource management plans and processes offer the solution and were the topic of the King Ranch Institute for Ranch Management's 2009 "Sixth Annual HOLT CAT ${ }^{\circledR}$ Symposium on Excellence in Ranch Management." The following papers are summaries of the presentations made at that symposium. No matter what size or type of organization you work in, I am confident that you will find them interesting and helpful.

Author is Associate Professor, King Ranch Institute for Ranch Management, Texas A $\Xi M$ University-Kingsville, Kingsville, TX 78363, USA, barry.dunn@tamuk.edu. 